\title{
Analysis of individualized education programs to quantify long-term educational needs following surgical intervention for single-suture craniosynostosis
}

\author{
Laura J Doshier MD, Arshad R Muzaffar MD, Kathleen KM Deidrick PhD, Gale B Rice PhD CCC-SLP
}

\begin{abstract}
LJ Doshier, AR Muzaffar, KKM Deidrick, GB Rice. Analysis of individualized education programs to quantify long-term educational needs following surgical intervention for single-suture craniosynostosis. Plast Surg 2015;23(1):31-34.

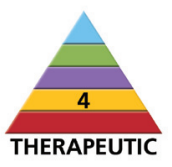

BACKGROUND: Single-suture craniosynostosis (SSC) is a common craniofacial condition with potential neurocognitive sequelae.

OBJECTIVE: To quantify any long-term functional academic and behavioural difficulties of children with SSC as indicated by the need for individualized education programs (IEPs), despite having undergone surgical treatment.

METHODS: Records of all school-age patients from 1992 to 2011 who underwent operative intervention for SSC were identified. Fifty-nine patients' guardians were contacted by telephone to provide informed consent for completion of a mailed standardized questionnaire querying demographic information as well as information regarding the patient's health, family and educational history; specifically whether the patient had ever been provided educational support as delineated in an IEP. The primary outcome measure was the history of the patient being assigned educational support as delineated in an IEP.

RESULTS: Thirty-seven consenting guardians completed and returned the standardized questionnaire (response rate 62.7\%). Twenty-one patients were male and 16 were female, with an age range of five to 14 years (mean age 10.2 years). Eleven (29.7\%) patients had a previous history of or currently were receiving educational support delineated in an IEP.

CONCLUSIONS: A higher proportion of school-age patients with a history of SSC (status postsurgical intervention) in the present study received educational support delineated in an IEP than the proportion of IEPs in the general student population of the United States (11.3\%).
\end{abstract}
L'analyse des programmes d'enseignement individualisé pour quantifier les besoins éducatifs à long terme après une intervention chirurgicale en raison d'une craniosténose à suture simple

Key Words: Craniosynostosis; Individualized education program

Single-suture craniosynostosis (SSC) is a common craniofacial con$\checkmark$ dition with potential neurocognitive sequelae. Because patients usually present in infancy and surgical correction is typically performed by one year of age, most of the research in this area has focused on neurodevelopment in preschool-age children (1-6). There is a relative paucity of data regarding the performance of these children in later school years. Such information would be valuable in anticipating potential educational difficulties in this population and in implementing the appropriate educational resources. Analyzing individualized education programs (IEPs) is one way to track what special education services these students are requiring because each IEP is "a written, legal document that describes all of the special education and related services that an eligible [United State's] student receives" (7). We hypothesized that elementary and secondary school-age children with a history of SSC require special education services as indicated by the need for IEPs in higher proportion than the general United States student population, despite having previously undergone surgical
HISTORIQUE : La craniosténose à suture simple (CSS) est un problème craniofacial courant qui s'associe à un potentiel de séquelles neurocognitives.

OBJECTIF : Quantifier les problèmes scolaires et comportementaux à long terme chez les enfants ayant une CSS, tels qu'ils sont indiqués par la nécessité de recourir à des programmes d'enseignement individualisé (PEI) malgré un traitement chirurgical.

MÉTHODOLOGIE : Les chercheurs ont extrait les dossiers de tous les patients d'âge scolaire qui ont subi une intervention chirurgicale en raison d'une CSS entre 1992 et 2011. Ils ont téléphoné aux tuteurs ou aux parents de 59 patients afin d'obtenir leur consentement éclairé et de leur poster un questionnaire standardisé sur la démographie et la santé des patients, leur famille et leurs antécédents éducatifs. Ils ont demandé si le patient a déjà reçu un soutien éducatif expliqué dans un PEI, ce qui constituait la mesure d'issue primaire.

RÉSULTATS : Trente-sept parents et tuteurs consentants ont rempli et envoyé le questionnaire standardisé (taux de réponse de 62,7 \%). Ainsi, 21 patients étaient des garçons et 16 des filles, et tous avaient de cinq à 14 ans (âge moyen de 10,2 ans). Onze patients (29,7 \%) avaient des antécédents de soutien éducatif expliqué dans un PEI ou recevaient encore un tel soutien.

CONCLUSIONS : Dans la présente étude, une plus forte proportion de patients d'âge scolaire ayant une histoire de CSS (intervention sur l'état postchirurgical) a reçu un soutien éducatif exposé dans un PEI que la proportion de PEI dans la population générale d'élèves des ÉtatsUnis $(11,3 \%)$.

treatment. Another aim of the present study was to describe which specific educational areas were targeted most frequently by the educational goals defined in the IEPs of these children.

\section{METHODS}

After obtaining approval from the University Health Sciences Institutional Review Board, the Division of Plastic Surgery's Craniofacial patient database was reviewed from May 1992 through December 2011. A total of 283 patients met the study inclusion criteria at the time of study commencement: school-age ( $\geq 5$ years of age), previous diagnosis of SSC and history of surgical intervention for craniosynostosis at the University Hospital. The patients' legal guardians were contacted by telephone and read a standardized script asking for their verbal consent to be mailed the standardized study questionnaire. The process of obtaining a waiver of documentation of consent had been completed through the university institutional review board. The study questionnaire asked the legal guardian about demographic

Division of Plastic Surgery, University of Missouri, Columbia, Missouri, USA

Correspondence: Dr Arshad R Muzaffar, Division of Plastic Surgery, University of Missouri, One Hospital Drive, Columbia, Missouri 65212, USA.

Telephone 573-882-2275, fax 573-884-4788, e-mail muzaffara@missouri.edu 
TABLE 1

\section{Standardized study questionnaire outline}

Demographics: Date of birth, age, sex, race/ethnicity, guardian's relationship to patient

Health history: Previous surgeries, medication history, medical history of: syndromes, difficulty sleeping, snoring, sleep apnea, vision/eye problems, hearing loss, seizures, attention deficit/hyperactivity, autistic spectrum disorder, pervasive developmental disorder, mood disorder(s)

Educational history: IQ assessment, type of school program, classroom setting, current supports, history of an individualized education program (IEP), goals of any IEP(s)

Family history: With whom the patient currently resides, highest level of education of guardian(s), current household income

information as well as information regarding the patient's health, family and educational history, specifically whether the patient had ever received educational support delineated in an IEP (outline of questionnaire in Table 1). Although guardians were directed to list all other medical diagnoses for the patient, specific questions regarding vision, hearing, seizures, sleeping and behavioural disorders were individually listed because difficulties in these areas could significantly alter a child's ability to learn. This information was also used to identify patterns of other problems arising in conjunction with the diagnosis of SSC. The patients' medical records were also retrospectively reviewed for details regarding specific diagnoses and operative management.

\section{RESULTS}

A total of 59 guardians were able to be contacted among the 283 patients (20.8\%) who met the study inclusion criteria. All guardians with whom contact was established consented to being mailed the standardized questionnaire; none refused participation outright. Thirty-seven completed questionnaires were returned, corresponding to a response rate of $62.7 \%$ among those guardians contacted. The mean patient age was 10.2 years (range five to 14 years). Twenty-one patients were male and 16 were female. Regarding race/ethnicity, one patient was identified as Asian, one as Hispanic, 34 as white/Caucasian and one failed to disclose. The guardians were also asked to disclose their minimum annual household income as: $<\$ 15,000 ; \$ 15,000$ to $\$ 29,999 ; \$ 30,000$ to $\$ 49,999 ; \$ 50,000$ to $\$ 74,999$; and $>\$ 75,000$. One respondent chose not to disclose this information; none were $<\$ 15,000$; two were $\$ 15,000$ to $\$ 29,999$; seven were $\$ 30,000$ to $\$ 49,999$; five were $\$ 50,000$ to $\$ 74,999$; and the majority $(n=22)$ of patients resided in a household earning $>\$ 75,000$.

Three different types of SSC comprised the sample population: nine unicoronal, 16 sagittal and 12 metopic. Three different attending surgeons were responsible for the 37 surgical interventions addressing the SSC and, of these operations, five involved open calvarial vault remodelling and 32 involved endoscopic strip craniectomies. The mean age of surgical intervention was 6.1 months overall, but the endoscopic strip craniectomies were performed at a relatively younger average patient age ( 4.0 months) than for those who underwent open calvarial vault remodelling (19.2 months of age). The average length of follow-up between time of operation until survey completion was 111.0 months (range 40.9 to 164.8 months).

An IEP was reportedly present for $11(29.7 \%)$ patients. The specific goals of each IEP varied among patients (Table 2). Goals related to improving communication, speech and or language were the most commonly represented of the goals (10 of 11 students with IEPs). Five patients were identified as being involved in a 'special' education setting for at least a portion of their school day. However, five guardians identified that their child was involved in a 'gifted' education setting for a portion of their school day. Of the remaining 27 patients, three were reported to be in solely a 'Homeschooled' educational setting and the other 24 were reported to be in strictly a 'General' educational
TABLE 2

Goals of an individualized education program (IEP)

\begin{tabular}{|c|c|c|c|c|c|}
\hline \multirow[b]{2}{*}{ Patient } & \multicolumn{5}{|c|}{ IEP goals } \\
\hline & $\begin{array}{l}\text { Communication, } \\
\text { speech, language }\end{array}$ & $\begin{array}{l}\text { Social } \\
\text { skills }\end{array}$ & $\begin{array}{l}\text { Activities of } \\
\text { daily living }\end{array}$ & Behaviour & $\begin{array}{l}\text { Academic } \\
\text { skills }\end{array}$ \\
\hline 1 & $x$ & & $x$ & & \\
\hline 2 & $x$ & & & $x$ & \\
\hline 3 & $x$ & & & & \\
\hline 4 & $\mathrm{x}$ & $x$ & & & \\
\hline 5 & $x$ & $x$ & $x$ & $x$ & $x$ \\
\hline 6 & $x$ & & & & $x$ \\
\hline 7 & $x$ & & & & \\
\hline 8 & $x$ & $x$ & $x$ & $x$ & $x$ \\
\hline 9 & $x$ & $x$ & $x$ & & $x$ \\
\hline 10 & $x$ & $x$ & & & \\
\hline 11 & & & & & $x$ \\
\hline Total, n & 10 & 5 & 4 & 3 & 5 \\
\hline
\end{tabular}

setting. Although the legal guardian(s) was the person completing each study questionnairre, inquiries were also made about the status of each child's biological parents, who may or may not have been the legal guardian(s) completing the questionnaire. The majority $(n=30)$ of children in the present study were residing with both of their biological parents, while five were living with one biological parent and two were described as living with an adoptive parent(s). In describing the legal guardians' education levels, nine patients had at least one guardian with an advanced (ie, Doctoral, Masters) degree, 21 had at least one guardian with a college degree and seven had a guardian(s) with high school or less the highest education level completed.

Finally, guardians were asked to describe other diagnoses held by their child. Thirteen $(35.1 \%)$ patients were described as having no other diagnoses aside from SSC; 13 (35.1\%) were described as wearing corrective lenses for vision problems; and 13 (35.1\%) were described as experiencing difficulty sleeping and/or snoring. One patient was diagnosed with each of the following: lower extremity malformation, thumb hypoplasia, hearing difficulties, anxiety disorder, oppositional defiant disorder, and an expressive and receptive language disorder. Two (5.4\%) patients had been diagnosed with attention deficit disorder and two (5.4\%) had been diagnosed with an autism spectrum disorder.

\section{DISCUSSION}

Neurocognitive development in patients with SSC has been the subject of considerable debate in the scientific literature. Initially, some authors asserted that the risk of a child with SSC developing neurocognitive deficits was no greater than for a child without a diagnosis of craniosynostosis $(1,8)$. Currently, however, consensus appears to favour the concept that these children are, in fact, at an increased risk for the development of neurocognitive deficits $(2,3,9,10)$. Studies involving functional testing measures, such as positron emission tomography scans (11) and auditory event-related potentials (12), support this contention by demonstrating measurable brain activity changes in children diagnosed with SSC. Other studies attempting to quantify and characterize these neurocognitive deficits have noted the following areas of concern for some children with SSC: speech and language $(4,13)$; motor development $(5,14)$; and attention, planning, processing speed and visual spatial skills (15). However, much of the published literature exploring the neurocognitive development of these children focuses on them at a very young age (ie, infants and toddlers) $(1-3,8-10)$. There is relatively little information regarding the longterm neurocognitive outcomes of children with SSC in the school setting, when a more complex array of intellectual tasks is required and more subtle deficiencies may become apparent. 
One way to investigate long-term outcomes for children with SSC is to determine whether these children have functional weaknesses that impact their school performance as they become older. The presence of an IEP for a specific child indicates that he or she is receiving educational services because IEPs are mandated in the United States by the Individuals with Disabilities Education Act for any child with a disability determined to be adversely affecting his or her educational progress (16). These "written, legal documents describe the special education services that a student receives" and "developing and implementing an IEP is one of the key steps taken by parents, teachers and school counselors to assist a student with special needs in obtaining educational services" (7). Therefore, by analyzing the content and, more specifically, the goals of an IEP, it is possible to determine what functional academic difficulties a child may possess. Goodman and Bond (17) agree with using IEPs as an assessment tool: "Since the time of their inception, IEPs have become more functionally dynamic: although the original purpose of the IEP was for it to serve as an accountability device, it has become an instructional as well as evaluative mechanism". The present study's intent was to quantify and analyze the IEPs in a sample population of children with SSC who had previously undergone surgical correction to provide more long-term outcome data regarding this populations' neurocognitive development. To our knowledge, prevalence rates of IEPs have not previously been reported as an outcome measure regarding SSC patients.

The present study's findings demonstrated that $29.7 \%$ of the sample population currently have, or have had in the past, special education support as delineated in an IEP despite undergoing surgical intervention for SSC. In contrast, normative data from the United States Department of Education statistics from 2011 to 2012 lists the "percent of K-12 students with an IEP in all school settings" as $11.3 \%$, a prevalence less than one-half of the present study's population (18). These findings support the conclusions of others that children with SSC manifest cognitive abnormalities long term $(2,3,9,10)$. Follow-up from surgery in the present study was 111.0 months (range 40.9 to 164.8 months), with an average patient age at survey completion of 10.2 years, which is longer than the follow-up of several other studies investigating this topic $(2,3,5,6,19)$. Additionally, unlike other studies, all of the patients in the present study underwent surgical intervention for their SSC $(2,10,19,20)$. It should be noted, however, that some authors contend that mental development in SSC may not be affected by surgical correction (2,9,20-23).

Previous published literature regarding long-term outcomes for these patients supports varied conclusions. Sidoti et al (19) performed a similar questionnaire-based study involving the parents of 36 children with metopic synostosis and concluded that "cognitive and behavioural abnormalities occur in at least a third of patients". This is a comparable proportion with the present study; however, only $58.3 \%$ of their sample population underwent any surgical intervention and $47.2 \%$ were $<5$ years of age. They also described that identified learning and/or behavioural problems increased with age. Kapp-Simon (2) longitudinally compared 84 children with SSC who both did and did not undergo surgery, and assessed outcomes with a combination of Bayley and McCarthy Scale evaluations but also reviewed school records for 34 of these patients who were school age: eighteen of 34 (53\%) who had adequate data to make a diagnosis exhibited a learning disorder or mental retardation. They also found learning disorders to be as frequent between those with no surgical correction versus those who had undergone surgical correction. Becker et al (10) performed a retrospective chart review of 214 patients with nonsyndromic craniosynostosis and found that "speech, cognitive and/or behavioral abnormalities were manifest in 49 percent of the patients" at an mean age of six years four months. However, not all of their patients exhibited SSC nor did all of their patients undergo surgical intervention. Kelleher et al (24) also had parents of 63 children with trigonocephaly complete a questionnaire and found speech and/or language delay in 34\% and that $47 \%$ were receiving "remedial or resource hours within the school system". Their sample population was from Ireland, whose educational system is levelled differently than that of the United States. However, the 47\% "receiving resources from within the school system" likely parallel a group of United States children who would be receiving aid from an IEP. Probably the most useful study in support of long-term deficits was conducted by Chieffo et al (25), who peformed neuropsychological testing of 65 unicoronal or sagittal synostosis patients at a minimum age of nine years (mean age 13 to 14 years), with all patients having undergone previous surgical intervention for their craniosynostosis (25). These children were compared with an age- and sex-matched control group with the conclusion that these patients "may still manifest lower than average results at long-term selective neuropsychological evaluations".

Other published studies contend that the deficits, if present, are subtle. Virtanen et al (22) surgically treated 18 patients with isolated sagittal synostosis and followed them long term ( 7.8 to 16.3 years of age), comparing them with a control group, and finding that "... except for the possibility of slight problems in language, the neurocognitive development in school-aged children operated on in infancy for scaphocephaly was within the average range". Shipster et al (13) agreed, stating in a longitudinal evaluation of 76 patients with isolated sagittal synostosis that, "There was no increased prevalence of global cognitive impairment in the group but there was a high prevalence rate of speech and/or language impairment (37\%)".

Beyond noting the prevalence of an IEP among the sample population, the present study also attempted to characterize any longterm neurocognitive deficits by querying the IEP goals for each of the 11 sample population patients with history of IEP. Ten of the 11 (90.9\%) patients had IEP goals related to "speech," "language" and/or "communication skills", otherwise no distinct patterns were present. This is similar to the findings of Shipster et al (13). However, other studies investigating specific areas of deficit are significantly more broad. A review article by Kapp-Simon et al (15) characterized the range of neuropsychological deficits most fully "problems with attention and planning, processing speed, visual spatial skills, language, reading and spelling". A survey of mothers conducted by Wong-Gibbons et al (26) noted beyond delays in cognitive development and difficulties with speech, the presence of "hearing loss and delays in emotional development". However, their patients were not separated into SSC versus multiple and syndromic populations commonly believed to have more severe deficits.

There were several limitations to the present study. There was no control group for comparison. It would have been valuable to compare the impact of surgery on the natural history of SSC by comparing the present study's population with a group of school-age children with SSC who had not been surgically treated. However, give the current longstanding practice in craniofacial surgery of treating patients with SSC in infancy, such a control group would not be readily obtainable. The sample size for the present study was also small; therefore, we were unable to report statistical significance for the several confounding variables, such as type of suture fused, open versus endoscopic surgical intervention or guardians' educational levels, etc. Apart from sample size, the characteristics of the sample population certainly do not represent all children with SSC. The majority $(91.9 \%)$ of this particular sample population designated themselves as Caucasian and $59.4 \%$ resided in househoulds earning a minimum annual income of $\$ 75,000$. This income is almost $150 \%$ of the median annual household income in 2011 of $\$ 50,054$ as detailed by the United States Census Bureau statistics (27). However, it has been described previously that low socioeconomic status alone may be causal in speech/language and cognitive impairments (28). In the present study, socioeconomic status did not appear to confound the results because the sample population was relatively affluent and Caucasian. Additionally, there was a wide range of time (approiximately 10 years) over which the children within this study population were educated and, thus, it is important to remember that criteria for educational diagnoses change over time and can also differ from state to state. The percentage of children in the present study with an IEP (29.7\%) may also underestimate the true prevalence of impairment in this population because not all children who would benefit from educational assistance are identified to receive an IEP. 


\section{CONCLUSIONS}

The present study adds to the existing body of literature demonstrating that children with SSC demonstrate long-term neurocognitive sequelae despite having undergone surgical intervention when younger. This sample population received educational support as delineated by IEPs in a higher proportion $(29.7 \%)$ than the prevalence of IEPs in the general student population of the United States (11.3\%).

DISCLOSURES: The authors have no financial disclosures or conflicts of interest to declare.

\section{REFERENCES}

1. Speltz ML, Endriga MC, Mouradian WE. Presurgical and postsurgical mental and psychomotor development of infants with sagittal synostosis. Cleft Palate Craniofac J 1997;34:374-9.

2. Kapp-Simon KA. Mental development and learning disorders in children with single-suture craniosynostosis. Cleft Palate Craniofac J 1998;35:197-203.

3. Gewalli F, Guimaraes-Ferreira JP, Sahlin P, et al. Mental development after modified pi procedure: Dynamic cranioplasty for sagittal synostosis. Ann Plast Surg 2001;46:415-20.

4. Warschausky S, Angobaldo J, Kewman D, Buchman S, Muraszko KM, Azengart A. Early development of infants with untreated metopic craniosynostosis. Plast Reconstr Surg 2005;11:1518-23.

5. Starr JR, Kapp-Simon KA, Cloonan YK, et al. Presurgical and postsurgical assessment of the neurodevelopment of infants with single-suture craniosynostosis: Comparison with controls. J Neurosurg 2007;107(2 Suppl):103-10.

6. Starr JR, Lin HJ, Ruiz-Correa S, et al. Little evidence of association between severity of trigonocephaly and cognitive development in infants with single-suture metopic synostosis. Neurosurgery 2010;67:408-15.

7. King A, Herron S, McKinstry R, et al. A multidisciplinary health care team's efforts to improve educational attainment in children with sickle-cell anemia and cerebral infarcts. J Sch Health 2006;76:33-7.

8. Kapp-Simon KA. Mental development in infants with nonsyndromic craniosynostosis with and without cranial release and reconstruction. Plast Reconstr Surg 1994;94:408-10.

9. Speltz ML, Kapp-Simon KA, Cunningham M, Marsh J, Dawson G. Single-suture craniosynostosis: A review of neurobehavioral research and theory. J Pediatr Psychol 2004;29:651-68.

10. Becker DB, Petersen JD, Kane AA, Cradock MM, Pilgram TK, Marsh JL. Speech, cognitive, and behavioral outcomes in nonsyndromic craniosynostosis. Plast Reconstr Surg 2005;116:400-7.

11. David LR, Genecov DG, Camastra AA, Wilson JA, Argenta LC. Positron emission tomography studies confirm the need for early surgical intervention in patients with single-suture craniosynostosis. J Craniofac Surg 1999;10:38-42.

12. Balan P, Kushnerenko E, Sahlin P, Huotilainen M, Naatanen R, Hukki J. Auditory ERPs reveal brain dysfunction in infants with plagiocephaly. J Craniofac Surg 2002;13:520-5.
13. Shipster C, Hearst D, Somerville A, Stackhouse J, Hayward R, Wade A. Speech, language, and cognitive development in children with isolated sagittal synostosis. Dev Med Child Neurol 2003;45:34-43.

14. Cohen SR, Cho DC, Nichols SL, Simms C, Cross KP, Burstein FD. American society of maxillofacial surgeons outcome study: Preoperative and postoperative neurodevelopmental findings in single-suture craniosynostosis. Plast Reconstr Surg 2004;114:841-7.

15. Kapp-Simon KA, Speltz ML, Cunningham ML, Patel PK, Tomita T. Neurodevelopment of children with single suture craniosynostosis: A review. Childs Nerv Syst 2007;23:269-81.

16. IDEA: Individuals With Disabilities Education Act, 20 U.S.C. $\S \S$ 1400, 1401, 1414. (2004). <www.law.cornell.edu/uscode/text/20/ chapter-33> (Accessed March 16, 2014).

17. Goodman JF, Bond L. The individualized education program: A retrospective critique. J Spec Educ 1993;26:408-22.

18. National Center for Education Statistics. Table 2. Number and percentage of all schools that had any students with an Individual Education Plan (IEP) because of special needs or formally identified disability, or who were English-lanugage learners (ELLs) or limitedEnglish profiecient (LEP), and percentage of students with an IEP/ formally identified disability or who were ELLs/LEP, by school type and selected school characteristics: 2011-12. <www.nces.ed.gov/ surveys/sass/tables/sass1112_2013312_s12n_002.asp> (Accessed March 1, 2014).

19. Sidoti EJ Jr, Marsh JL, Marty-Grames L, Noetzel MJ. Long-term studies of metopic synostosis: Frequency of cognitive impairment and behavioral disturbances. Plast Reconstr Surg 1996;97:276-82.

20. Kapp-Simon KA, Figueroa A, Jocher CA, Schafer M. Longitudinal assessment of mental development in infants with nonsyndromic craniosynostosis with and without cranial release and reconstruction. Plast Reconstr Surg 1993;92:831-9.

21. Hayward R, Jones B, Evans R. Functional outcome after surgery for trigonocephaly. Plast Reconstr Surg 1999;104:582-3.

22. Virtanen R, Korhonen T, Fagerholm J, Viljanto J. Neurocognitive sequelae of scaphocephaly. Pediatrics 1999;103:791-5.

23. Lekovic GP, Bristol RE, Rekate HL. Cognitive impact of craniosynostosis. Semin Pediatr Neurol 2004;11:305-10.

24. Kelleher MO, Murray DJ, McGillivary A, Kamel MH, Allcutt D, Earley MJ. Behavioral, developmental, and educational problems in children with nonsyndromic trigonocephaly. J Neurosurg 2006;105(5 Suppl):382-4.

25. Chieffo D, Tamburrini G, Massimi L, et al. Long-term neuropsychological development in single-suture craniosynostosis treated early. J Neurosurg Pediatr 2010;5:232-7.

26. Wong-Gibbons DL, Kancherla V, Romitti PA, et al. Maternal reports of satisfaction with care and outcomes for children with craniosynostosis. J Craniofac Surg 2009;20:138-42.

27. DeNavas-Walt C, Proctor BD, Smith JC. Income, Poverty, and Health Insurance Coverage in the United States: 2011. Current Population Reports. Issued September 2012. <www.census.gov/ prod/2012pubs/p60-243.pdf> (Accessed March 1, 2014).

28. Walker D, Greenwood C, Hart B, Carta J. Prediction of school outcomes based on early language production and socioeconomic factors. Child Dev 1994;65:606-21. 